\title{
Exploring the Effects of Value Added Services on Perceived Value of Mobile Payment in the UK
}

\author{
Hassan Alhallaq, Muhammad Younas, Samia Kamal, and Bob Champion \\ Oxford Brookes University, Oxford, UK \\ hhallaqegmail.com \\ \{m.younas, skamal, rchampion\}@brookes.ac.uk
}

\begin{abstract}
Mobile payment (m-payment) apps have been introduced as an innovative alternative payment method that extends in-store payment options available to consumers. Despite being marketed as convenient and secure, recent research reports that $\mathrm{m}$-payment uptake has gone far below earlier forecasts. This is due to consumers perceiving little added value relative to existing payment options, such as contactless cards. Augmenting m-payment with value added services (VAS) has been suggested as a way to add value to m-payment and boost demand. However, empirical investigation about the role and effect of VAS on consumers' perceptions of m-payment value remains scant. This study attempts to fill this gap by employing a deductive qualitative approach through the lens of perceived value theory, extended with perceived trust and risk. A total of 23 interviews were conducted with UK adopters and nonadopters of mpayment. The findings suggest that the perceived added value of the augmented m-payment service was mainly derived from utilitarian values associated with the additional functionalities offered by VAS. Additionally, the augmentation of m-payment has enhanced perceptions of trust in the service provider as a result of integrating additional features that tackle issues associated with the payment experience. This study advances knowledge of the concept of added value in the $\mathrm{m}$-payment context and provides practical suggestions to m-payment providers for increasing the consumer perceived value.
\end{abstract}

Keywords: Mobile Payment, Perceived Value, Value Added Services.

\section{Introduction}

The rapid technological advances in the past decade have changed the payments landscape worldwide. As a result, new payment instruments, such as mobile and wearable devices, have emerged as convenient and secure alternatives to traditional cards and cash payment methods for in-store payments. However, the success of these alternatives is heavily influenced by consumers' decisions to change their longstanding payment behaviours. Although mobile devices have achieved a massive success as reflected in penetration rates among consumers worldwide, their mobile payment (mpayment) apps appear to be lagging far behind. Recent market research reveals that proximity m-payment in the UK is far from mass adoption [1]. This is despite the fact 
that the main proximity m-payment wallet apps (Apple Pay, Android Pay, Samsung Pay) natively provided by the dominant global mobile handset manufacturers were commercially introduced within the past four years in the UK. Previous studies suggested that perceptions of risk involved in the use of proximity m-payment act as a strong barrier to adoption among UK consumers [2]. On the other hand, it has been repeatedly argued that consumers' reluctance to change their old payment habits is due to seeing no added value in m-payment as compared to traditional payment methods $[3,4,5]$. This appears to be particularly relevant to the case of the UK, where the increasing popularity of contactless cards has arguably made m-payment as a less valued alternative among consumers [6]. However, the way consumers would perceive m-payment added value has not been fully investigated by existing research.

Value maximization is regarded as the basic assumption in examining the consumer's eventual behaviour since potential adopters of new digital services play the dual role of technology users and consumers [7]. Therefore, with a set of multiple options, consumers often seek to maximize their utility or enjoyment from the consumption of a given market offering [8]. This implies that determinants of consumer choice decisions are subjectively evaluated on a net value basis perceived in a given option relative to other alternatives. Findings from previous research have concluded that augmenting the m-payment service with value added services (VAS) might add value to $\mathrm{m}$-payment and promote demand $[3,4,8]$. Although these findings offer useful insights into the potential effect of VAS in increasing the value of m-payment, supporting empirical evidence confirming this effect among consumers is still lacking. This study aims to fill this gap by addressing the following research question: What is the effect and role of VAS on the perceived value of m-payment from a consumer's perspective? In doing so, we employed the perceived value theory extended with perceived trust in provider and perceived risk as our theoretical foundation. We conducted a qualitative investigation in the UK to explore how consumers perceive the added value of augmenting proximity m-payment apps with three exemplified VAS suggested by previous studies: instant account balance, loyalty cards integration, and cashback. Our key findings indicate that the perceived added value of the augmented m-payment app has been largely interpreted in terms of the additional convenience, monetary and trust benefits brought by the extra features of the VAS. These findings highlight the importance of addressing other activities involved in the payment experience. The remainder of this paper is organized as follows. In section 2 we lay out the theoretical foundation of the study, followed by the research methodology in section 3 . The results and findings are presented in section 4 . In section 5 , the paper concludes with the research implications and provides directions for future research.

\section{Theoretical Background and Related Work}

Existing m-payment adoption research has offered a rich investigation into the factors that affect adoption decisions among consumers using well-established information systems (IS) theories, such as TAM (Technology Acceptance Model) and UTAUT (Unified Theory of Acceptance and Use of Technology) [10]. Although this body of 
research has been useful in terms of highlighting factors related to the characteristics of m-payment as a technology, some researchers argued that theories from other disciplines should be used to explore other factors pertinent to the adoption of $\mathrm{m}$ payment as a new interactive payment experience that coexists with other widely used payment methods [e.g. 10,11]. This study responds to this call by employing the perceived value theory, which has roots in marketing literature, as a suitable theoretical lens that fits the aim of investigation.

\subsection{Perceived Value Theory and its Determinants}

Perceived value has been used to explain behavioural intentions towards different technologies [e.g. 7,12]. Conceptually, perceived value has emerged in marketing literature as the trade-off between a combination of multiple determinants of benefits and sacrifices as perceived by consumers in a market offering [13]. As the definition suggests, value is subjectively weighed by consumers for what they receive against what they give to acquire and use a product. Following on previous value-based technology adoption research [e.g. 14,15], we draw on the seminal PERVAL model of Sweeney and Soutar [16] and consider the determinants of benefits as functional, social, and enjoyment values. The functional value has been conceptualized as two separate utilitarian values that consumers derive from performance-related attributes and monetary gains perceived in a product or service [16]. While the performance aspect of functional value is derived from the convenience of fulfilling a task, monetary gains represent the time and money saved as a result of using mobile services [14]. Convenience value appears to be of a particular importance within the context of m-payment due to the ubiquity of the mobile phone [17]. Therefore, we define convenience value as the consumer's perceived utility from the ease of acquiring and using m-payment as a service accessible anytime and anywhere. Similarly, a positive relationship has been confirmed between perceived economic benefits and use of $\mathrm{m}$ payment for in-store shopping [15]. Thus, we define monetary value as the consumer's perceived utility of the money savings resulting from the use of m-payment. Consumer behaviour research suggests that consumer's choice is influenced by experiential aspects represented in enjoyment and social values in addition to the utilitarian goals [18]. The enjoyment aspect of value, also termed as emotional or hedonic, is conceptualized as the product or service capability to arouse feelings or affective states [19]. We therefore define enjoyment value as the positive feelings that the consumer derives from interacting with m-payment apps. The social value reflects the extent to which a product or service enhances social self-image and interpersonal communication in a social setting [16,19]. Previous studies have confirmed the influence of social value on perceived value of proximity m-payment [12]. In a similar vein, we define social value as a source of self-appreciation perceived from the impression conveyed by peers in a social context with regard to the use of m-payment. In addition, we augment the above determinants of value with perceived trust in service provider as a benefit and perceived risk as a nonmonetary sacrifice due to their profound effect on consumer intentions to transact using technology-based environments [20]. Since the interaction between consumers and m-payment providers lacks 
direct personal communication, trust beliefs in providers play an essential role in choosing their services. The value created by perceived trust results from the benefits received through interacting with a competent and benevolent provider in addition to the role of trust in reducing uncertainties involved in service use [21]. Moreover, previous studies have shown that perceptions of risk exhibited a salient effect on the perceived value of m-payment $[12,15]$.

\subsection{The Concept of Added Value}

Different approaches have been suggested in marketing literature to increase the value of a market offering relative to competitors [22]. Zeithaml [13] broadly argues that added value can be achieved by increasing perceptions of benefits or reducing perceptions of sacrifices in a given product. On the other hand, Grönroos [23] has distinguished between core value brought by the core solution and added value resulting from the additional services. The author has also conceptualized additional services as the VAS offered along with the core service to enhance its perceived value and minimize the associated monetary and nonmonetary costs. In this sense, the concept of added value can be regarded as a multidimensional construct that includes both functional and emotional benefits as perceived by consumers [22]. Therefore, it could be argued that added value can be realized directly through perceived gains or indirectly as a result of reducing sacrifices or both. In this study, we explore how consumers perceive added value in proximity m-payment augmented with VAS through the lens of the theorized determinants of value extended with perceived trust and risk.

\section{$3 \quad$ Methodology and Data Collection}

The subjective nature of the concept of value and the relative newness of VAS in the m-payment context have led to the decision to use a qualitative research approach using semi-structured interviews. Qualitative methods have been suggested in IS research as a suitable approach for understanding the meanings a given system has for its users and unveil the processes involved in causal relationships [24]. Snowball sampling technique was utilized by asking participants invited through university research groups and social contacts to share the invitation with their contacts. The selection criteria were set to include participants who use a smartphone, regardless of previous m-payment experience, and were residents of the UK. The interview guide was first piloted with two PhD students and their comments were taken into consideration to clarify questions that had not been fully understood. A total of 23 interviews were conducted between November 2017 and April 2018, with an average duration of 37 minutes. Table 1 provides a summary of the characteristics of the participants.

The final interview guide comprised three sections. In the first section, participants were briefed about the aim of the study and asked general demographic questions. In the second section, participants were presented with the definition of each of the theorized determinants of perceived value followed by questions about their perceptions of the presented determinant in terms of using m-payment as a sole service. This 
method allowed participants to define each value determinant in their own words and contextualize their answers around the use scenarios of m-payment.

Table 1. Demographics of Participants

\begin{tabular}{|l|l|l|l|}
\hline Measure & Group & $\begin{array}{l}\text { Number of } \\
\text { participants }\end{array}$ & $\begin{array}{l}\text { m-payment } \\
\text { adopters }\end{array}$ \\
\hline Age & $18-24$ & 4 & 1 \\
& $25-34$ & 11 & 5 \\
& $35-44$ & 6 & None \\
& $45-54$ & 1 & 1 \\
& $55-60$ & 1 & None \\
\hline Gender & Male & 16 & 5 \\
& Female & 7 & 2 \\
\hline Occupation & Full-time Employment & 12 & 3 \\
& Full-time student & 10 & 4 \\
& Retired & 1 & None \\
\hline
\end{tabular}

In the third section, three VAS have been chosen for this study based on suggestions from previous research and relevance to the UK market, namely instant account balance [3], loyalty card integration [9], and cashback rewards [25]. Following the introduction of the open banking initiative in the UK in January 2018, regulated thirdparty payment service providers will be able to provide account information services to consumers upon their consent [26]. It is thus of a great importance to understand how consumers would perceive value in future m-payment apps featuring instant account balance. The choice of loyalty card integration stemmed from the popularity of loyalty programs provided by high street retailers in the UK. Although some existing m-payment wallet apps offer the functionality of storing loyalty cards, understanding its effect on m-payment value is scarce. Finally, the cashback reward was chosen based on previous research suggesting that UK consumers are encouraged to use proximity m-payment apps that offer financial incentives [2]. Each of the suggested VAS was introduced to participants followed by questions about their perceptions of using m-payment augmented with the given value added service in terms of the value determinants. The purpose was to elicit their views about each of the suggested services individually. Interview recordings were transcribed and content-analysed using Nvivo 11 software. Data analysis involved labelling segments of the transcripts with descriptive codes that summarize the participant's views about the topic addressed in each segment. The codes were then categorized under the respective value theme that corresponded to one of the theorized value determinants. As coding and data collection took place simultaneously, the sampling continued until a data saturation point has been reached, where no new codes could be identified.

\section{$4 \quad$ Results and Findings}

Though the interview questions covered both the use of m-payment as a standalone service and m-payment augmented with VAS, this paper focuses on the results and 
findings of the latter. However, a summary of the findings relating to the use of mpayment as a sole service will be presented to contrast the effect of the VAS. More details about these findings can be found in our previous study [5].

\subsection{Convenience Value}

Most m-payment adopters have expressed their perception of convenience of proximity m-payment as a sole service in terms of the ubiquity of the mobile phone, the speed and ease of making m-payment, and the time and effort saved from not having to handle physical cards. Conversely, most nonadopters considered m-payment as more time consuming and less convenient compared to contactless card payment. Augmenting m-payment with an instant balance service was perceived by some participants as an added convenience for saving the time and effort needed to check the balance using different channels: "it means that I don't have to go to different places to find the same information" (P11). In addition, participants embraced the convenience of getting real-time balance updates after each purchase as compared to card payments that, in some instances, take longer to take effect. Integrating loyalty cards with mpayment was perceived by most participants as an added convenience value in terms of easier manageability of loyalty cards of different retailers in one place and reduced transaction time at check-out: "you currently have to hand over two cards... so there is no question that it would factually speedup the process plus you would never forget them" (P19). On the other hand, some participants noted that the need to scan a digital version of the loyalty card stored on the mobile phone does not offer much advantage in terms of convenience over scanning the physical card. They suggested that the integration should be seamless, where the m-payment app recognizes the retailer being paid for and transfers the points to the respective stored loyalty card. A few participants, who were familiar with cashback schemes, mentioned that having cashback integrated with a m-payment app would simplify the process of claiming cashback and locating deals through the app. In this sense, they recognized convenience in terms of the app's capability to contextually identify and suggest cashback deals based on location and payment patterns: "...if I am in town deciding where to eat then my first thought would be my app to see if there are any offers that I can claim" (P20).

\subsection{Monetary Value}

An overwhelming majority of the participants, regardless of their previous experience with m-payment, saw no monetary value from using proximity m-payment as a sole service. In contrast, participants perceived an added monetary value from seeing the account balance before making a payment as it would help to reduce 'blind' payments resulting from the absence of actual cash: "Having lost cash, I and everyone I know has become a bit more lax with how they spend money ... I think for me all of the savings come from an intuitive understanding of: do I have enough money to afford the treat of $x$ today?" (P7). Additionally, some participants anticipated that seeing the balance before and after the payment would help more with budgeting rather than being a means of direct money saving. However, participants who seemed to be orga- 
nized in terms of their finances were hesitant to recognize any monetary gains from checking their balance before or after payments. The added monetary value that participants perceived in m-payment augmented with loyalty cards was based on simplifying the process of earning loyalty points. They mentioned that loyalty points are frequently missed because they often forget scanning loyalty cards at checkout. Having loyalty cards of different retailers visible alongside payment cards was observed as an efficient way to increase utilization of loyalty schemes: "it would be easier for you to use them to collect points" (P17). The cashback service was dominantly embraced by many participants as a financial incentive to use m-payment apps. The monetary value that participants perceived seems to outweigh their negative perceptions of reduced convenience from using the app: "I suppose if it does make the paying process in anyway longer or more convoluted then ... it's definitely an inconvenience that I would put up to save a bit of money" (P15). These findings demonstrate the potential high impact of monetary value on the perceived value of m-payment.

\subsection{Enjoyment Value}

Convenience related factors have generally emerged as the main drivers of enjoyment regardless of m-payment augmentation with VAS. The participants perceived enjoyment of $\mathrm{m}$-payment as a frictionless and fast-paced experience. However, they perceived additional affective values based on the extra features of VAS. Receiving balance updates in real-time was regarded as an emotional benefit for being worry-free about their finances and eliminating the need to check balances through different channels: "It would just make me have a greater quality of life, it would just be another thing that I don't have to do every week because I am already doing it every time I pay" (P20). Likewise, simplifying the management of loyalty cards in one app and being rewarded with loyalty points were regarded as an additional positive emotional benefit of the app. On the other hand, participants were very enthusiastic about the attainable monetary gains of the cashback service: “...I think getting the money back would certainly make you enjoy [m-payment] and it would give extra pennies to do other things that you would enjoy" (P4). This finding suggests monetary value as another possible source of m-payment enjoyment.

\subsection{Social Value}

Participants were split over attaching a social value to the use of proximity $\mathrm{m}$ payment as a sole service. While a few participants perceived that using m-payment would enhance their social image among their peers who use the service, many others argued that they don't pay much attention to how others think of them when it comes to how they pay. Some participants noted that they might care about impressions on others if they were younger. Although some of the participants mentioned that discussing one or more of the suggested VAS within their social groups might influence their perception about the service, however, they seemed to be reluctant to acknowledge any significant social value relating to their image per se. Compared to other value perceptions, the less significant interpretation of the social value could be 
attributed to the sensitivity of discussing financial matters in a social context, as was mentioned by one participant: "I am British we don't talk about our money! Whether it would enhance their view of me or not I am not convinced that it would" (P21).

\subsection{Perceived Trust}

Participants expressed their perceptions of trust in proximity m-payment providers in terms of the provider's business size as an indication of the popularity of their products, whether they are regulated by a local authority, or their reputation with regards to previous security breaches. Furthermore, the introduction of m-payment VAS has led to additional trust-enhancing perceptions in providers. Different measures were used by participants to describe the added trust value of augmenting m-payment apps with instant balance, mainly including the increased transparency about their financial information and making it easier to have balance information in a payment app: "To put it all in the same place for you to view and use that does go to a level of trust for not hiding anything behind anything" (P11). On the other hand, augmenting mpayment with loyalty schemes or cashback was considered as an indication of collaboration between m-payment providers and the retailers offering these incentives. In this context, the participants considered a m-payment app provider as more trustworthy since it is trusted by the retailers they are familiar with: "It might make me more inclined to trust them because if they've got partnerships with major stores that is obviously even more legit than you would hope" (P12). Additionally, addressing issues encountered with the payment experience in other payment methods, such as the absence of cash and the difficulty of managing multiple loyalty accounts, were perceived as additional trust-enhancing factors: "I would tend to trust the provider more because I would think that they have looked up at what customers wanted" (P16).

\subsection{Perceived Risk}

Nonadopters exhibited higher perceptions of risk on using m-payment as a sole service compared to adopters who repeatedly characterized the risks as avoidable. Three main themes have emerged under perceived risk: identity and payment information theft, privacy concerns, and the risk of running out of the phone battery. The growing news reports of data privacy breaches in recent years seem to have a significant impact on privacy concerns for many participants to use m-payment. This was also evident in perceptions of potential privacy issues associated with augmenting m-payment with instant balance and loyalty card integration. Many participants were reluctant to allow third-party m-payment providers access to their balance information due to their concerns about data misuse. They added that instant balance service is safe only if provided by their bank: "If [the provider] has got access to what is your balance, then I probably want it to be my bank" (P9). In contrast, some participants appeared to be more open to the service by relating the decision to share their balance information to the trustworthiness of the provider. This highlights the salient effect of trust in provider on reducing the perceived risks. Similarly, although most participants perceived little or no risks associated with the integrated loyalty cards service, one participant 
expressed his concerns about the possibility of making his shopping information available to the m-payment app provider: "I don't necessarily want [the m-payment app provider] to know where I am with the GPS on my phone, how much I am spending through the data on my card, and what I am spending it on through the data on my loyalty card" (P19). On the other hand, most participants perceived no additional risks associated with the cashback service. One participant stated that cashback gives him a reason to accept the risks he perceives in m-payment: "It doesn't reduce the downside risk, but it adds something on the positive side to balance against it" (P6).

\subsection{Ranking of VAS}

Having identified the participants' value perceptions of the proposed VAS, we sought to understand their most appealing value propositions in terms of the theorized value determinants. One approach was to ask them to rank the three VAS in order of preference and explain the reason of their choice. Table 2 summarizes the participants' main reasons for choosing the most preferred value added service.

Table 2. Participants' reasons for choosing the most preferred value added service

\begin{tabular}{|l|l|l|l|}
\hline $\begin{array}{l}\text { Top-ranked value } \\
\text { added service }\end{array}$ & $\begin{array}{l}\text { Number of } \\
\text { participants }\end{array}$ & Reasons of choice & Value construct \\
\hline Instant balance & 8 & $\begin{array}{l}\text { Real-time account balance } \\
\text { Easier account management } \\
\text { Restore money tangibility }\end{array}$ & $\begin{array}{l}\text { Convenience } \\
\text { Convenience } \\
\text { Convenience + } \\
\text { Monetary } \\
\text { Monetary }\end{array}$ \\
\hline Cashback & 7 & $\begin{array}{l}\text { Easier to find deals } \\
\text { Saving money }\end{array}$ & $\begin{array}{l}\text { Convenience } \\
\text { Monetary }\end{array}$ \\
\hline $\begin{array}{l}\text { Loyalty cards integra- } \\
\text { tion }\end{array}$ & 6 & $\begin{array}{l}\text { Easier loyalty management } \\
\text { Saving money }\end{array}$ & $\begin{array}{l}\text { Convenience } \\
\text { Monetary }\end{array}$ \\
\hline None & 2 & No additional value & None \\
\hline
\end{tabular}

The instant balance was ranked as the most preferred value added service by the highest number of participants, closely followed by cashback and loyalty card integration. Two of the participants did not give any preference to any of the suggested VAS due to seeing no value that fits their needs. The relationship between the reasons and the related value constructs indicates that convenience and monetary values were the main drivers for choosing a given value added service. This finding further emphasizes the importance of utilitarian values in m-payment services.

\section{$5 \quad$ Analysis and Discussion}

\subsection{Theoretical implications}

This study has provided a rich interpretation of the added value concept in m-payment context. The findings indicate that the added value of m-payment augmentation with 
VAS was mainly perceived through the dimensions of utilitarian values, i.e. convenience and monetary. Particularly, the added convenience value was perceived through the ability to achieve more with the m-payment app on top of a streamlined payment experience. Embedding more functionalities, such as the instant balance and loyalty accounts, into a frequently used payment app was seen as more time saving than accessing these services through separate channels. In addition, the suggested VAS were perceived to be solving usability issues associated with the payment activity, such as the visibility of paid money and the inconvenience of handling multiple loyalty cards. More interestingly, monetary value was only perceived from using the augmented mpayment service either directly from earning cashback or indirectly from simplifying ways of budgeting, collecting loyalty points, or finding cashback deals. Although this finding differs from earlier studies that conceptualize utilitarian values under a unified determinant [e.g. 12], differentiating between convenience and monetary values as two separate constructs has proved to be important since the monetary value has received no support in case of the sole m-payment service. Therefore, it could be argued that VAS do not only enhance existing perceived values of the core m-payment service but also create new values based on the additional features.

Perceptions of enjoyment value followed the same pattern of influence for the augmented and nonaugmented m-payment service. In both cases, enjoyment value was mainly derived as a consequence of convenience-related dimensions rather than being a main value determinant as indicated by previous studies [e.g. 15]. One possible explanation to this finding could be the pure utilitarian nature of $\mathrm{m}$-payment services, where more emphasis is placed on fulfilling the payment task while the emotional aspect is recognized as a positive side effect of how the task was fulfilled [5]. Additionally, the added monetary value has also led to positive emotional aspects among some participants. No major changes were observed in terms of the influence of social value following the augmentation of m-payment service. In comparison with other value dimensions, participants appeared to be less encouraged to attach significant self-image aspects from using m-payment in general. Although this finding is in contrast with previous studies [e.g. 12,15], however, our findings suggest that privacy and age-related considerations seem to inhibit noticeable social gains. Furthermore, the augmentation of m-payment with VAS has enhanced perceptions of trust in $\mathrm{m}$ payment providers. Understanding consumer needs by adding extra features that simplify payment scenarios was perceived as a trust-enhancing factor. On the other hand, the augmentation of m-payment does not seem to reduce the perceived associated risks. However, almost all participants acknowledged that their perceptions of risk diminish with a trustworthy provider. Given that this association is confirmed by previous studies [e.g. 20], therefore, we can argue that augmenting m-payment with VAS may indirectly reduce perceptions of risk through enhancing perceptions of trust in provider.

\subsection{Practical implications}

The findings of this study offer several implications for m-payment providers regarding how consumers perceive added value in m-payment services. First, m-payment 
providers should reconsider the concept of added value beyond the performance characteristics of the core payment service. Involving additional services that tackle issues associated with existing payment scenarios has proved to be pivotal in recognizing the added value of $\mathrm{m}$-payment from a consumer's perspective as compared to existing payment methods. Second, more efforts are needed to understand consumer activities involved in the whole payment experience. As the findings suggest, different consumers exhibited different needs associated with their payment activities. Therefore, mpayment providers should invest in business initiatives that promote consumer engagement and value co-creation. Finally, to alleviate the negative impact of risk perceptions, more marketing efforts are needed to highlight the security advantages that m-payment solutions are built with relative to traditional payment methods.

\subsection{Conclusion and future research}

This study advances the existing body of knowledge about m-payment adoption using a value-based approach. The perceived value theory has been employed to understand the effect of m-payment VAS on the different determinants of value. In light of our findings, the added value perceived from m-payment augmentation with VAS was mainly interpreted in terms of convenience and monetary values in addition to enhanced trust perceptions in m-payment providers. The added enjoyment value was predominantly envisaged as a resulting emotional effect of convenience-related aspects rather than a substantial value determinant. Although the findings of this study present a rich account of the concept of added value in m-payment context, we suggest that these findings should be used to guide the development of future quantitative value-based m-payment studies due to the small sample size that characterizes this qualitative study. In addition, the current study was based on three pre-suggested VAS. Therefore, future research is encouraged to follow a more consumer-focused approach that derives possible VAS from participants based on their individual needs.

\section{References}

1. eMarketer: UK: Mobile Payments Still Looking to Grab a Foothold, https://www.emarketer.com/newsroom/index.php/uk-mobile-payments-grab-foothold, last accessed 12/11/2018.

2. Slade, E., Williams, M., Dwivedi, Y. and Piercy, N.: Exploring consumer adoption of proximity mobile payments. Journal of Strategic Marketing 23(3), 209-223 (2015).

3. Hayashi, F.: Mobile payments: What's in it for consumers?. Federal Reserve Bank of Kansas City. Economic Review, 35-66 (2012).

4. Madureira, A.: Factors that hinder the success of SIM-based mobile NFC service deployments. Telematics and Informatics 34(1), 133-150 (2017).

5. Alhallaq, H., Younas, M., Kamal, S. and Champion, B.: Understanding Perceived Value of Mobile Payments: A Qualitative Study. In: $24^{\text {th }}$ UK Academy for Information Systems Conference Proceedings (2019).

6. Titcomb, J.: Mobile payments struggle to make impact on contactless card use. The Telegraph, https://www.telegraph.co.uk/technology/2017/04/14/mobile-payments-strugglemake-impact-contactless-card-use, last accessed 15/09/2017. 
7. Kim, H. W., Chan, H. C. and Gupta, S.: Value-based Adoption of Mobile Internet: An empirical investigation. Decision Support Systems 43(1), 111-126 (2007).

8. Au, Y. A. and Kauffman, R. J.: The economics of mobile payments: Understanding stakeholder issues for an emerging financial technology application. Electronic Commerce Research and Applications 7(2), 141-164 (2008).

9. De Reuver, M., Verschuur, E., Nikayin, F., Cerpa, N. and Bouwman, H.: Collective action for mobile payment platforms: A case study on collaboration issues between banks and telecom operators. Electronic Commerce Research and Applications 14(5), 331-344 (2015).

10. Dahlberg, T., Guo, J. and Ondrus, J.: A critical review of mobile payment research. Electronic Commerce Research and Applications 14(5), 265-284 (2015).

11. Arvidsson, N.: Consumer attitudes on mobile payment services - results from a proof of concept test. International Journal of Bank Marketing 32(2), 150-170 (2014).

12. Cocosila, M. and Trabelsi, H.: An Integrated Value-Risk Investigation of Contactless Mobile Payments Adoption. Electronic Commerce Research and Applications 20, 159170 (2016).

13. Zeithaml, V. A.: Consumer perceptions of price, quality, and value: a means-end model and synthesis of evidence. The Journal of marketing , 2-22 (1988).

14. Pihlström, M. and Brush, G. J.: Comparing the perceived value of information and entertainment mobile services. Psychology \& Marketing 25(8), 732-755 (2008).

15. de Kerviler, G., Demoulin, N. T. M. and Zidda, P.: Adoption of in-store mobile payment: Are perceived risk and convenience the only drivers?. Journal of Retailing and Consumer Services 31, 334-344 (2016).

16. Sweeney, J. and Soutar, G.: Consumer perceived value: the development of a multiple item scale. Journal of Retailing 77(2), 203-220 (2001).

17. Zhou, T.: An empirical examination of continuance intention of mobile payment services. Decision Support Systems 54(2), 1085-1091 (2013).

18. Holbrook, M. B. and Hirschman, E. C.: The Experiential Aspects of Consumption: Consumer Fantasies, Feelings, and Fun. Journal of Consumer Research 9(2), 132 (1982).

19. Sheth, J. N., Newman, B. I. and Gross, B. L.: Why We Buy What We Buy. Journal of Business Research 22, 159-171 (1991).

20. Pavlou, P.: Consumer Acceptance of Electronic Commerce: Integrating Trust and Risk with the Technology Acceptance Model. International Journal of Electronic Commerce 7(3), 69-103 (2003).

21. Sirdeshmukh, D., Singh, J. and Sabol, B.: Consumer Trust, Value, and Loyalty in Relational Exchanges. Journal of Marketing 66(1), 15-37 (2002).

22. de Chernatony, L., Harris, F. and Dall'Olmo Riley, F.: Added value: its nature, roles and sustainability. European Journal of Marketing 34(1/2), 39-56 (2000).

23. Grönroos, C.: Value-driven relational marketing: From products to resources and competencies. Journal of Marketing Management 13(5), 407-419 (1997),

24. Kaplan, B. and Maxwell, J.: Qualitative research methods for evaluating computer information systems. In: Evaluating the organizational impact of healthcare information systems, 30-55, Springer, New York (2005).

25. Apanasevic, T., Markendahl, J. and Arvidsson, N.: Stakeholders' expectations of mobile payment in retail: lessons from Sweden. International Journal of Bank Marketing 34(1), 37-61 (2016)

26. Zachariadis, M. and Ozcan, P.: The API economy and digital transformation in financial services: The case of open banking. Working paper, SWIFT Institute, London (2017). 